\title{
SPDT discrete switch design using switchable SIW resonators for millimeter wave MIMO transceiver
}

\author{
Amirul Aizat Zolkefli ${ }^{1}$, Badrul Hisham Ahmad ${ }^{2}$, Noor Azwan Shairi ${ }^{3}$, Adib Othman ${ }^{4}$, \\ Zahriladha Zakaria ${ }^{5}$, Imran Bin Mohd Ibrahim ${ }^{6}$, Huda Bin A. Majid ${ }^{7}$ \\ 1,2,3,5,6 Microwave Research Group (MRG), Centre for Telecommunication Research and Innovation (CeTRI), \\ Fakulti Kejuruteraan Elektronik dan Kejuruteraan Komputer (FKEKK), Melaka, Malaysia \\ ${ }^{4}$ Fakulti Teknologi Kejuruteraan Elektrik dan Elektronik (FTKEE), Universiti Teknikal Malaysia Melaka (UTeM), \\ Melaka, Malaysia \\ ${ }^{7}$ Faculty of Engineering Technology, Universiti Tun Hussein Onn Malaysia (UTHM), Johor, Malaysia
}

\section{Article Info}

Article history:

Received Jan 20, 2021

Revised Oct 27, 2021

Accepted Nov 1, 2021

\section{Keywords:}

Millimeter wave

SIW resonator

SPDT switch

Substrate integrated waveguide

Switchable resonator

\begin{abstract}
A single pole double throw (SPDT) discrete switch design using switchable substrate integrated waveguide (SIW) resonators is proposed in this paper. It was designed for the millimeter wave multiple input multiple output (MIMO) transceiver. An example application is for $5 \mathrm{G}$ communication in $26 \mathrm{GHz}$ band. High isolation between transmitter and receiver (in the transceiver) is needed in SPDT switch design to minimize any high radio frequency (RF) power leakage in the receiver. Therefore, the use of switchable SIW resonators can achieve higher isolation if compared to the conventional series SPDT switch, where the isolation of the proposed SPDT is depend on the bandstop response of the SIW resonators. The switchable SIW resonators can be switched between allpass and bandstop responses to allow the operation between transmit and receive modes. As a result, the simulation and measurement showed that the proposed SPDT switch produced an isolation higher than $25 \mathrm{~dB}$ from 24.25 to $27.5 \mathrm{GHz}$ compared to the conventional design.
\end{abstract}

This is an open access article under the CC BY-SA license.

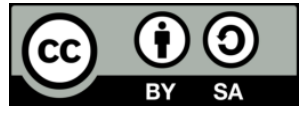

\section{Corresponding Author:}

Badrul Hisham Ahmad

Microwave Research Group (MRG), Centre for Telecommunication Research \& Innovation (CeTRI) Fakulti Kejuruteraan Elektronik dan Kejuruteraan Komputer (FKEKK), Universiti Teknikal Malaysia Melaka (UTeM), Hang Tuah Jaya, 76100, Durian Tunggal, Melaka, Malaysia

Email: badrulhisham@utem.edu.my

\section{INTRODUCTION}

In a front-end system of wireless communication, the single pole double throw (SPDT) switch is used to switch between transmit and receive modes in time division duplex (TDD) communication. As depicted in Figure 1, it is an example use of the SPDT in millimeter wave multiple input multiple output (MIMO) transceiver architecture [1]. This architecture is proposed for $5 \mathrm{G}$ millimeter wave communications where the SPDT switches need to be connected to 5G MIMO antennas [2], [3]. Therefore, the need for high isolation between transmitter and receiver is one of the key parameters in SPDT switch design to minimize any high radio frequency $(\mathrm{RF})$ power leakage from transmitter to receiver that could distort the active circuits of the receiver, particularly low noise amplifier (LNA).

There are three techniques from literature that are mostly used to achieve high isolation in the design of SPDT switches; first, through configuration of the switch [4], [5]; second, switch element material and manufacturing process [6], [7]; and third, resonated switch element with inductance or capacitance elements [8], [9]. The first technique is widely used either by configuring it in the multiple cascaded shunt [4] 
or the combination of series and shunt elements [5], [10]. The multiple cascaded shunt SPDT is usually spaced with quarter wavelength of transmission lines and ideally used for high-power application. The key concern of this technique, however, is increasing the SPDT circuit size and consuming more current to turn-on the switch elements (eg. PIN diodes). For the second technique, an example can be found in [7], where high isolation of the SPDT switch is based on GaN high-electron mobility transistor (HEMT) technology with MOCVD-grown $\mathrm{AlGaN} / \mathrm{GaN}$ heterostructure on $100-\mathrm{mm}$ semi-insulating $\mathrm{SiC}$ substrates. These materials and modern manufacturing process, however, often complicate the process of fabrication and would increase the costs. Then, for the third technique, an example can be found in SPDT switch design for the improved isolation by using a section of transmission line (equivalent to capacitance) in series with a single shunt PIN diode [9]. This technique reduces the parasitic inductance in the PIN diode near the resonant frequency. As a result, at that specific frequency, it improves the isolation performance. This technique, however, limiting the isolation bandwidth because of the single resonant tank circuit of inductance and capacitance.

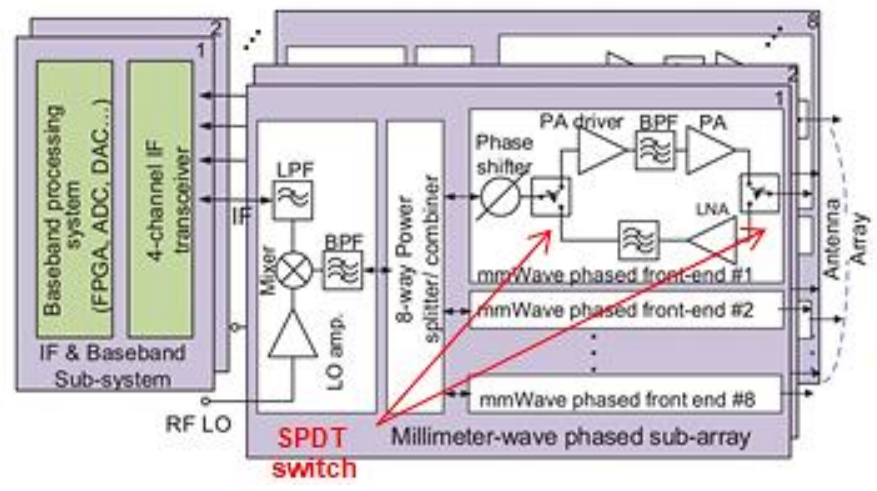

Figure 1. SPDT switch in a millimeter wave MIMO transceiver architecture [1]

In microwave and millimeter wave spectrums, substrate integrated waveguide (SIW) is found to be a suitable choice for designing and developing the components such as power divider [11], filter [12] and antenna [13]: because it has compact dimensions, low insertion loss, high-quality factor (QF), and can easily integrate with planar RF components [14]. On the other hand, there are several switchable designs for millimeter wave MIMO such as switchable diplexer [15], switchable low noise amplifier (LNA) [16] and switchable antenna [17]. Besides, our previous works proposed the use of switchable microstrip resonator in RF switch design (SPDT and DPDT) for isolation improvement [18], [19] and multiband isolation [20], [21].

Therefore, in the application of millimeter wave MIMO transceiver [1], this paper proposes a SPDT discrete switch design using switchable SIW resonators. The switchable SIW resonators can be switched between allpass and bandstop responses where the isolation of the SPDT depends on the bandstop response of the SIW resonators. The proposed SPDT switch is operated in $26 \mathrm{GHz}$ band and targeted for millimeter wave MIMO transceiver for $5 \mathrm{G}$ communication. Besides that, a conventional series SPDT was designed and simulated as a reference to the proposed SPDT switch for isolation performance comparison.

\section{CIRCUIT DESIGN}

\subsection{Switchable SIW resonator}

The switching of the SIW resonator in Figure 2 is performed by using discrete PIN diode to allow the switching between bandstop and allpass responses. The bandstop of the resonator is operated due to the resonant frequency of quarter wavelength $(\lambda / 4)$ of the open stub SIW transmission line. The PIN diode is operated by two distinct states which are ON state $(+5 \mathrm{~V})$ and OFF state $(-5 \mathrm{~V})$. The PIN diode of the SIW resonator is supplied with $+5 \mathrm{~V}$, which allows allpass response and is supplied with $-5 \mathrm{~V}$ for switching to a bandstop response (for isolation performance).

In the SIW design, via holes form a major part of the SIW to realize the bilateral edge walls. Via holes are the most important discontinuities in multilayered circuits. Therefore, in designing via holes of the SIW resonator, the equations in [22] were used. The via hole dimension must follow the calculation of the diameter (d) of the via and the pitch (p) between the via. The calculated dimension is to ensure that the radiation leakage will be maintained at a very low amount and with that SIW can be designed almost similar to the conventional rectangular waveguide with the appropriate dimension of $\mathrm{p}$ and $\mathrm{d}$. 
For millimeter wave MIMO transceiver in $26 \mathrm{GHz}$ band, four switchable SIW resonators as illustrated in Figure 3 that based on the design in [23]. These resonators (S1, S2, S3 and S4) are resonated at $24.25,25.33,26.42$ and $27.5 \mathrm{GHz}$ respectively. These resonant frequencies are expected to cover for $5 \mathrm{G}$ communication in $26 \mathrm{GHz}$ band [24]. Each resonator is separated by an impedance inverter (k-inverter) which uses a quarter wavelength $(\lambda / 4)$ of microstrip lines (K1, K2 and K3). This circuit can be switched between bandstop and allpass responses by using PIN diodes (D1, D2, D3 and D4). The detailed operation of this circuit is reported and discussed in [23].

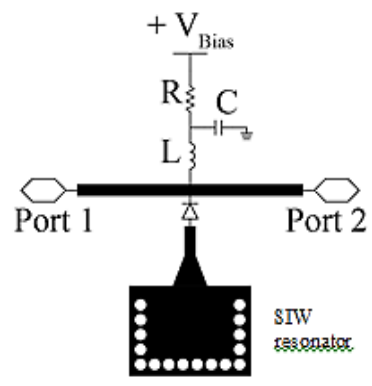

Figure 2. The proposed switchable SIW resonator

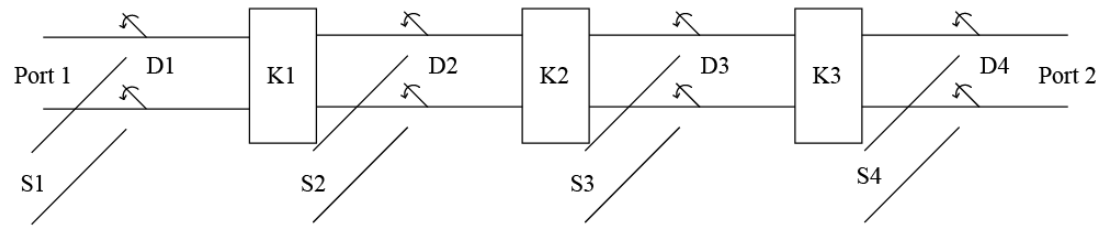

Figure 3. Equivalent circuit of allpass (OFF state) and bandstop (ON state) responses

\subsection{SPDT switch design}

The conventional series SPDT switch and the proposed SPDT switch are shown in Figure 4(a) and Figure 4(b) respectively. The conventional series SPDT was designed and simulated as a reference to the proposed SPDT switch for isolation performance comparison. As shown in Figure 4(a), during transmit mode (RF signals propagate from port 1 to port 2), the isolation of the series SPDT switch is totally depend on the OFF state of the series PIN diode in receive arm.

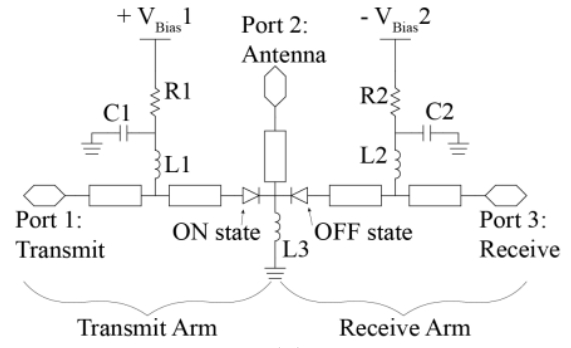

(a)

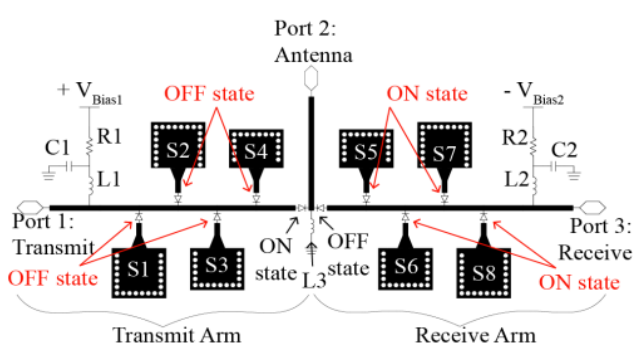

(b)

Figure 4. The (a) conventional series SPDT switch and (b) proposed SPDT switch

Meanwhile, during transmit mode operation of the proposed SPDT switch (Figure 4(b)), in the transmit arm, all PIN diodes on SIW resonators are turned OFF. Then, all the resonators in transmit arm become an allpass response. In the receive arm, all PIN diodes on SIW resonators are turned ON. Then, all the resonators in receive arm become a bandstop response. In this transmit mode, the isolation between port 3 and port 1 (S31) depends on the bandstop response and also the OFF state of the series PIN diode in the receive arm.

During receive mode operation of the proposed SPDT switch, RF signals propagate from port 2 to port 3. Therefore, in receive arm, all PIN diodes in SIW resonators are turned OFF. Then, all the resonators in receive arm become an allpass response. While in transmit arm, all PIN diodes in SIW resonators are turned ON. Then, 
all the resonators in transmit arm become a bandstop response. In this receive mode, the isolation between port 1 and port 3 (S31) depends on the bandstop response and also the OFF state of the series PIN diode in the transmit arm. These operations, for transmit and receive modes are summarized in Table 1.

The proposed SPDT switch circuit in Figure 4(b) was constructed in computer simulation technology (CST) software. All the parameters of Roger RT/duroid 5880 substrate such as thickness of $0.254 \mathrm{~mm}$ and relative dielectric constant of 2.2 were included in the microstrip line and the SIW model of the circuit design. The circuit was simulated in terms of insertion loss, return loss and isolation. For the actual fabrication and measurement, the commercial PIN diodes (MADP 000907-14020W) were used to control between transmit and receive modes. The fabricated of the proposed design is shown in Figure 5 . The total layout area is $77 \times 33 \mathrm{~mm}$.

Table 1. Transmit and receive modes operation in the

\begin{tabular}{|c|c|c|}
\hline & Transmit Mode & Receive Mode \\
\hline $\mathrm{V}_{\text {Bias }} 1$ & $+5 \mathrm{~V}$ & $-5 \mathrm{~V}$ \\
\hline $\mathrm{V}_{\text {Bias }} 2$ & $-5 \mathrm{~V}$ & $+5 \mathrm{~V}$ \\
\hline $\begin{array}{l}\text { Series PIN diode } \\
\text { (transmit arm) }\end{array}$ & ON state & OFF state \\
\hline $\begin{array}{l}\text { Series PIN diode } \\
\text { (receive arm) }\end{array}$ & OFF state & ON state \\
\hline $\begin{array}{l}\text { SIW Resonators } \\
\text { (transmit arm) }\end{array}$ & $\begin{array}{l}\text { Allpass } \\
\text { response }\end{array}$ & $\begin{array}{l}\text { Bandstop } \\
\text { response }\end{array}$ \\
\hline $\begin{array}{l}\text { SIW Resonators (receive } \\
\text { arm) }\end{array}$ & $\begin{array}{l}\text { Bandstop } \\
\text { response }\end{array}$ & $\begin{array}{l}\text { Allpass } \\
\text { response }\end{array}$ \\
\hline
\end{tabular}

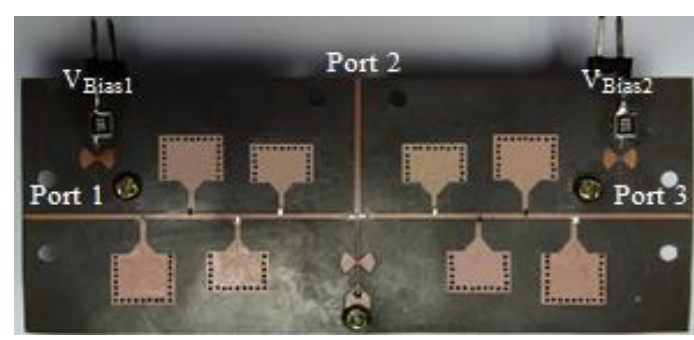

Figure 5. Prototype of the proposed SPDT switch with the total area of $77 \times 33 \mathrm{~mm}$

\section{RESULTS AND DISCUSSION}

\subsection{Switchable SIW resonator}

For better understanding of the characteristic of the switchable SIW resonator structure, the analysis was done with a single SIW resonator (Figure 2). The circuit configuration was simulated with a length of SIW resonator, $l=4.8 \mathrm{~mm}$ (resonated at $27.5 \mathrm{GHz}$ ), the diameter of the via, $d=0.75 \mathrm{~mm}$ and the pitch between the via, $p=1.0 \mathrm{~mm}$. Figures $6(\mathrm{a})$ and (b) show the allpass and bandstop responses at $27.5 \mathrm{GHz}$ of the switchable SIW resonator. In Figure 6(a) (allpass), the return loss (S11) was more than $20 \mathrm{~dB}$ at $27.5 \mathrm{GHz}$ and the insertion loss $(\mathrm{S} 21)$ was less than $1 \mathrm{~dB}$. While in bandstop response in Figure 6(b), the return loss (S11) was less than $1 \mathrm{~dB}$ and the attenuation (S21) was more than $25 \mathrm{~dB}$ and the bandstop bandwidth of the resonator was around $2 \mathrm{GHz}($ at $-3 \mathrm{~dB}$ ). This bandstop response was used as an isolation performance in SPDT switch. Thus, higher isolation of SPDT switch could be achieved by properly design the structure of the SIW resonator.

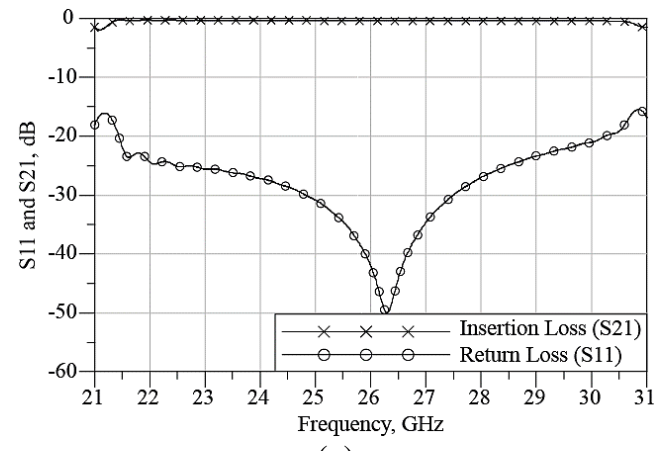

(a)

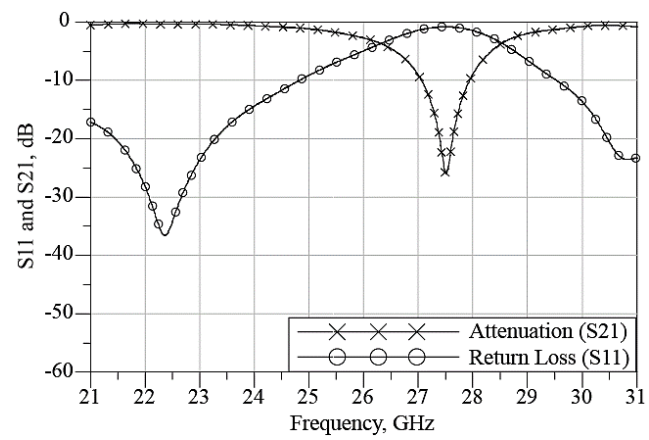

(b)

Figure 6. Switchable SIW resonator during (a) allpass response and (b) bandstop response

\subsection{SPDT switch}

Figures 7 and 8 are the simulated results of the conventional SPDT switch and the proposed SPDT switch for the return loss (S11), insertion loss (S21) and isolation (S31) respectively. The switch circuit is symmetrical between transmit arm and receive arm, hence only the performance results in transmit mode are discussed in this paper. Figure 7(a) shows the return loss (S11) for both SPDT switches in the transmit arm. The simulated results of return loss in the conventional SPDT switch and the proposed SPDT switch are more than $12 \mathrm{~dB}$ and $14 \mathrm{~dB}$ respectively from 24.25 to $27.5 \mathrm{GHz}$ frequency. This showed that the proposed 
SPDT switch exhibited better return loss performance compared to the conventional SPDT switch. As shown in Figure 7(b), the simulated results of insertion loss (S21) for the conventional SPDT switch and the proposed SPDT switch are almost the same response. For maximum power from transmit port to antenna port, it should have low insertion loss with an acceptable return loss. Thus, it can be seen that the SPDT switches managed to achieve less than $1.5 \mathrm{~dB}$ of insertion loss from 24.25 to $27.5 \mathrm{GHz}$ frequency.

As depicted in Figure 8, it can be observed that the proposed SPDT switch managed to get better isolation (S31); more than $25 \mathrm{~dB}$ between port 3 to port 1 as compared to the conventional SPDT switch where the isolation was just around 15 to $18 \mathrm{~dB}$ from 24.25 to $27.5 \mathrm{GHz}$. As reported in [25], more than 25 $\mathrm{dB}$ isolation of SPDT switch is required for high power application to weaken any high RF power leakage between transmit and receive arms. Figure 9 shows the measurement results for the proposed SPDT switch. In the $26 \mathrm{GHz}$ band $(24.25$ to $27.5 \mathrm{GHz})$, it managed to achieve more than $11 \mathrm{~dB}$, less than $3.9 \mathrm{~dB}$ and more than $30 \mathrm{~dB}$ for return loss, insertion loss and isolation respectively. This shows that the measurement results were in good agreement with simulation results.

The circuit performance comparison between the proposed SPDT switch and conventional SPDT switch; and the comparison between simulation and measurement results for the proposed SPDT switch are listed in Table 2. The comparison was made at the center frequency of $25.875 \mathrm{GHz}$ in the $26 \mathrm{GHz}$ band for $5 \mathrm{G}$ millimeter wave communications. Therefore, the proposed SPDT switch design could be integrated with other millimeter wave sub-components such as antenna array [26], [27], bandpass filters [28], [29] and power amplifers [30], [31] for a complete system design of $5 \mathrm{G}$ millimeter wave communications as depicted in Figure 1.

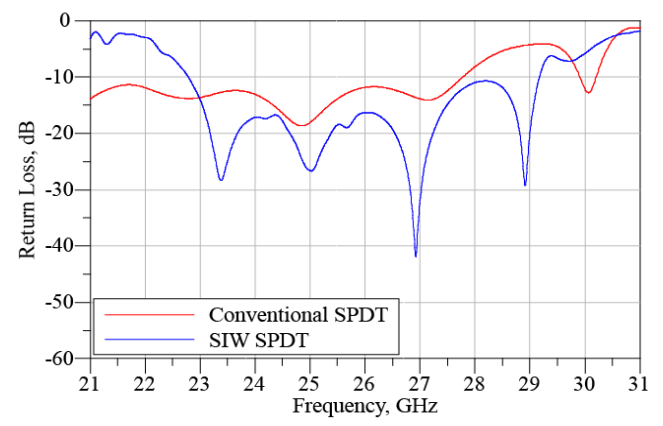

(a)

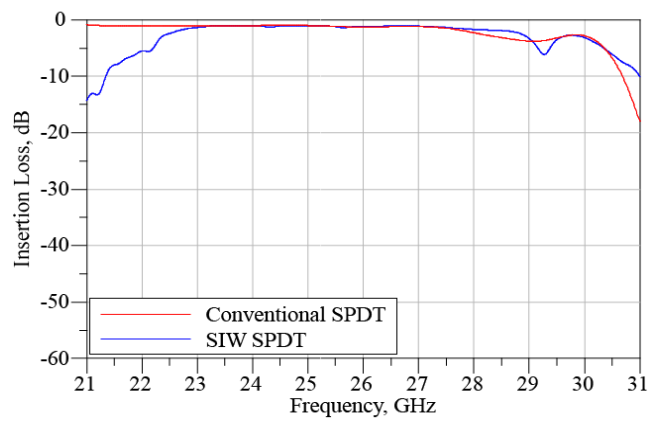

(b)

Figure 7. The (a) simulated return loss (S11) and (b) insertion loss (S21) results

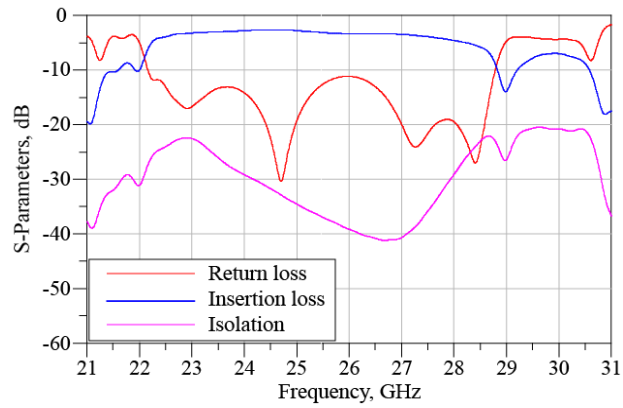

Figure 8. Simulated isolation (S31) results

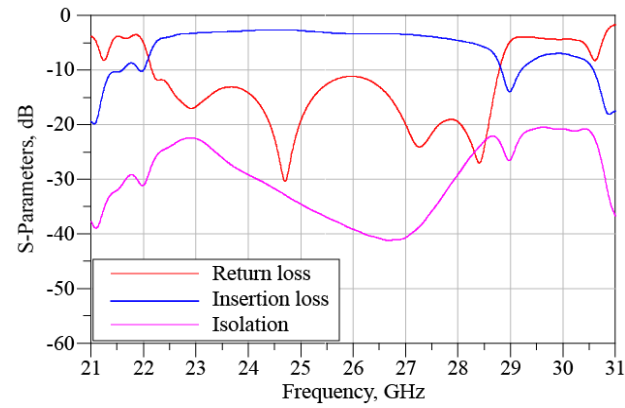

Figure 9. Measurement results (proposed design)

Table 2. Circuit performance comparison for the proposed SPDT switch and conventional switch

\begin{tabular}{lccc} 
& Return Loss (S11) at & Insertion Loss (S21) at & Isolation (S31) at \\
& $25.875 \mathrm{GHz}, \mathrm{dB}$ & $25.875 \mathrm{GHz}, \mathrm{dB}$ & $25.875 \mathrm{GHz}, \mathrm{dB}$ \\
\hline SPDT switch with switchable & $16(\mathrm{sim})$ & $1.2(\mathrm{sim})$ & $42(\mathrm{sim})$ \\
SIW resonators & 11 (meas) & $3.4($ meas $)$ & 38 (meas) \\
Conventional SPDT switch & $12(\mathrm{sim})$ & $1.2(\mathrm{sim})$ & $17(\mathrm{sim})$ \\
\hline
\end{tabular}

\section{CONCLUSION}

The SPDT discrete switch design using switchable SIW resonators was successfully designed and simulated in CST software. The isolation of the proposed SPDT switch and the conventional SPDT switch 
was compared where the different isolation performance between these two SPDT switch designs are very significant. The proposed SPDT switch was then fabricated for verification. It was successfully demonstrated that the proposed design produced isolation, higher than $25 \mathrm{~dB}$ in $26 \mathrm{GHz}$ band (from 24.25 to $27.5 \mathrm{GHz}$ ) as compared to the conventional design.

\section{ACKNOWLEDGEMENTS}

The authors would like to greatly express their thanks and appreciation to the Centre for Research and Innovation Management (CRIM) and Universiti Teknikal Malaysia Melaka (UTeM) for their encouragement and help to complete this research work. The publication of this paper was funded under the research grant: PJP/2020/FKEKK/H123/S01721.

\section{REFERENCES}

[1] B. Yang, Z. Yu, J. Lan, R. Zhang, J. Zhou, and W. Hong, "Digital Beamforming-Based Massive MIMO Transceiver for 5G Millimeter-Wave Communications," IEEE Transactions on Microwave Theory and Techniques, vol. 66, no. 7, pp. 3403-3418, July 2018, doi: 10.1109/TMTT.2018.2829702.

[2] Y. Rahayu, I. P. Sari, D. I. Ramadhan, and R. Ngah. "High gain 5G MIMO antenna for mobile base station," International Journal of Electrical \& Computer Engineering (2088-8708), pp. 468-476, vol. 9, no. 1, 2019, doi: 10.11591/ijece.v9i1.pp468-476.

[3] S. F. Jilani, Q. H. Abassi and A. Alomainy, "Millimetre-Wave MIMO Array of a Compact Grid Antenna for 5G Wireless Networks and Beyond," 2020 International Conference on UK-China Emerging Technologies (UCET), Glasgow, United Kingdom, 2020, pp. 1-4, doi: 10.1109/UCET51115.2020.9205326.

[4] L. Zhang, X. Cheng, X. Deng, and X. Li, "Design of K/Ka-band passive HEMT SPDT switches with high isolation," 2017 China Semiconductor Technology International Conference (CSTIC), Shanghai, 2017, pp. 1-3, doi: 10.1109/CSTIC.2017.7919890.

[5] Y. Gong, J. W. Teng, and J. D. Cressler, "A Compact, High-Power, 60 GHz SPDT Switch Using Shunt-Series SiGe PIN Diodes," 2019 IEEE Radio Frequency Integrated Circuits Symposium (RFIC), Boston, MA, USA, pp. 15-18, 2019, doi: 10.1109/RFIC.2019.8701812.

[6] T. Shivan et al., "220-325 GHz high-isolation SPDT switch in InP DHBT technology," Electronics Letters, vol. 54, no. 21, pp. 1222-1224, 2018, doi: 10.1049/el.2018.6028.

[7] F. Thome, P. Brückner, R. Quay, and O. Ambacher, "Millimeter-Wave Single-Pole Double-Throw Switches Based on a 100-nm Gate-Length AlGaN/GaN-HEMT Technology," 2019 IEEE MTT-S International Microwave Symposium (IMS), Boston, MA, USA, pp. 1403-1406, 2019, doi: 10.1109/MWSYM.2019.8700955.

[8] J. Park, W. Lee, and S. Hong, "A Small-Size K-Band SPDT Switch Using Alternate CMOS Structure With Resonating Inductor Matching," IEEE Microwave and Wireless Components Letters, vol. 30, no. 11, pp. 1093-1096, Nov. 2020, doi: 10.1109/LMWC.2020.3026389.

[9] A. Singh and M. K. Mandal, "Parasitic Compensation and Hence Isolation Improvement of PIN Diode-Based Switches," IEEE Transactions on Circuits and Systems II: Express Briefs, vol. 68, no. 1, pp. 97-101, Jan. 2021, doi: 10.1109/TCSII.2020.3000587.

[10] S. Jang, S. Kong, H. Lee, J. Park, K. Kim, and K. Lee, "28 GHz 1.8 dB Insertion Loss SPDT Switch with 24 dB Isolation in $65 \mathrm{~nm}$ CMOS," 2018 48th European Microwave Conference (EuMC), Madrid, pp. 835-838, 2018, doi: 10.23919/EuMC.2018.8541696.

[11] T. G. Siang, D. P. David Dass, S. Z. Ibrahim, M. N. A. Karim, and A. A. Dewani. "Design of Ku-band power divider using Substrate Integrated Waveguide technique," Bulletin of Electrical Engineering and Informatics, vol. 8, no. 1, pp. 172-179, 2019, doi: 10.11591/eei.v8i1.1410.

[12] K. B. Kumar and T. Shanmuganantham, "Wideband SIW filter for mm-wave applications," 2017 International Conference on Computer, Communication and Signal Processing (ICCCSP), Chennai, 2017, pp. 1-5, doi: 10.1109/ICCCSP.2017.7944075.

[13] Y. M. Hussein et al., "Substrate integrate waveguide and microstrip antennas at $28 \mathrm{GHz}$," Bulletin of Electrical Engineering and Informatics, vol. 9, no. 6, pp. 2462-2468, 2020, doi: 10.11591/eei.v9i6.2190.

[14] A. Iqbal, J. J. Tiang, S. K. Wong, M. Alibakhshikenari, F. Falcone, and E. Limiti, "Miniaturization Trends in Substrate Integrated Waveguide (SIW) Filters: A Review," IEEE Access, vol. 8, pp. 223287-223305, 2020, doi: 10.1109/ACCESS.2020.3044088.

[15] H. Mizutani, R. Ishikawa, and K. Honjo, "A Novel Sub-6-GHz and 28-GHz GaN Switchable Diplexer MMIC for Carrier Aggregation with Massive MIMO Full Duplex Link," 2019 IEEE Asia-Pacific Microwave Conference (APMC), Singapore, 2019, pp. 1429-1431, doi: 10.1109/APMC46564.2019.9038453.

[16] J. Heredia et al., "Miniature Switchable Millimeter-Wave BiCMOS Low-Noise Amplifier at 120/140 GHz Using an HBT Switch," Micromachines, vol. 10, no. 10, p. 632, 2019, doi: 10.3390/mi10100632.

[17] O. Jo, W. Kwon, and W. Hong, "Achieving 360 Degree Coverage Dynamic and Switchable Beamforming through Resource-Efficient Switchable Antennas for Future mmWave IoT Devices," IEEE Transactions on Industrial Electronics, vol. 68, no. 9, pp. 8982-8991, Sept. 2021, doi: 10.1109/TIE.2020.3020022.

[18] N. A. Shairi, Z. Zakaria, A. M. S. Zobilah, B. H. Ahmad, and P. W. Wong, "Design of SPDT switch with transmission line stub resonator for WiMAX and LTE in $3.5 \mathrm{GHz}$ band," Journal of Engineering and Applied Sciences, vol. 11, no. 5, pp. 3198-3202, 2016. 
[19] N. A. Shairi, B. H. Ahmad, and P. W. Wong, "SPDT discrete switch design using switchable radial stub resonator for WiMAX and LTE in $3.5 \mathrm{GHz}$ band," 2013 IEEE International RF and Microwave Conference (RFM), Penang, 2013, pp. 1-5, doi: 10.1109/RFM.2013.6757205.

[20] A. M. Zobilah, Z. Zakaria, and N. A. Shairi, "Selectable multiband isolation of single pole double throw switch using transmission line stub resonator for WiMAX and LTE applications," IET Microwaves, Antennas \& Propagation, vol. 11, no. 6, pp. 844-851, 2016, doi: 10.1049/iet-map.2016.0868.

[21] M. Y. Algumaei, N. A. Shairi, Z. Zakaria, A. M. S. Zobilah, and B. H. Ahmad, "Analysis of Open Stub Resonator and its Application in Dual Isolation Band of SPDT Switch Design," International Journal of Electrical \& Computer Engineering, vol. 6, no. 6, pp. 2088-8708, 2016, doi: 10.11591/ijece.v6i6.pp2900-2910.

[22] D. Deslandes and K. Wu, "Design consideration and performance analysis of substrate integrated waveguide components," 2002 32nd European Microwave Conference, EuMC 2002, no. 2, 2002, pp. 3-6, doi: 10.1109/EUMA.2002.339426.

[23] A. A. Zolkefli et al., "Switchable bandstop to allpass filter using cascaded transmission line SIW resonators in Kband," Bulletin of Electrical Engineering and Informatics, vol. 10, no. 5, pp. 2617-2626, 2021, doi: 10.11591/eei.v10i5.2835.

[24] J. Lee et al., "Spectrum for 5G: Global Status, Challenges, and Enabling Technologies," IEEE Communications Magazine, vol. 56, no. 3, pp. 12-18, March 2018, doi: 10.1109/MCOM.2018.1700818.

[25] C. M. Hu et al., "Design of an RF transmit/receive switch using LDMOSFETs with high power capability and low insertion loss," IEEE Transactions on Electron Devices, vol. 58, no. 6, pp. 1722-1727, 2011, doi: 10.1109/TED.2011.2127481.

[26] S. Zhu, H. Liu, Z. Chen, and P. Wen, "A Compact Gain-Enhanced Vivaldi Antenna Array With Suppressed Mutual Coupling for 5G mmWave Application," IEEE Antennas and Wireless Propagation Letters, vol. 17, no. 5, pp. 776-779, May 2018, doi: 10.1109/LAWP.2018.2816038.

[27] I. Lima de Paula et al., "Cost-Effective High-Performance Air-Filled SIW Antenna Array for the Global 5G 26 GHz and $28 \mathrm{GHz}$ Bands," IEEE Antennas and Wireless Propagation Letters, vol. 20, no. 2, pp. 194-198, Feb. 2021, doi: 10.1109/LAWP.2020.3044114.

[28] M. G. Bautista, H. Zhu, X. Zhu, Y. Yang, Y. Sun, and E. Dutkiewicz, "Compact Millimeter-Wave Bandpass Filters Using Quasi-Lumped Elements in 0.13- um (Bi)-CMOS Technology for 5G Wireless Systems," IEEE Transactions on Microwave Theory and Techniques, vol. 67, no. 7, pp. 3064-3073, July 2019, doi: 10.1109/TMTT.2019.2895581.

[29] L. Gao and G. M. Rebeiz, "Wideband Bandpass Filter for 5G Millimeter- Wave Application in 45-nm CMOS Silicon-onInsulator," IEEE Electron Device Letters, vol. 42, no. 8, pp. 1244-1247, Aug. 2021, doi: 10.1109/LED.2021.3089656.

[30] T. Li and H. Wang, "A Continuous-Mode 23.5-41GHz Hybrid Class-F/F-1 Power Amplifier with 46\% Peak PAE for 5G Massive MIMO Applications," 2018 IEEE Radio Frequency Integrated Circuits Symposium (RFIC), pp. 220-230, 2018, doi: 10.1109/RFIC.2018.8429030.

[31] T. Li, M. Huang, and H. Wang, "Millimeter-Wave Continuous-Mode Power Amplifier for 5G MIMO Applications," IEEE Transactions on Microwave Theory and Techniques, vol. 67, no. 7, pp. 3088-3098, July 2019, doi: 10.1109/TMTT.2019.2906592.

\section{BIOGRAPHIES OF AUTHORS}

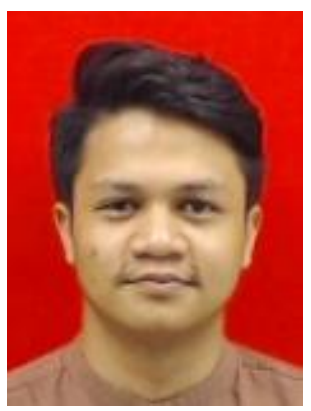

Amirul Aizat Zolkefli was born in Malaysia in 1996. He is a postgraduate student pursuing his Master's degree in Electronic Engineering at Universiti Teknikal Malaysia Melaka (UTeM). His research interest is in RF and Microwave Engineering. Currently, he is doing research on SPDT switch by using discrete PIN diode and switchable SIW resonator for 5G millimeter wave communication.

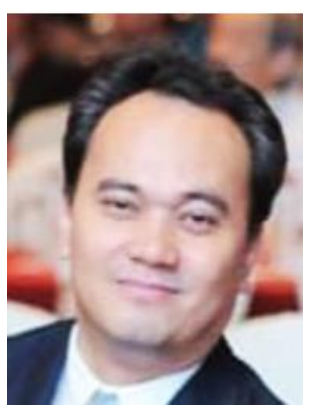

Badrul Hisham Ahmad graduated with honours degree in Electronic and Communication Engineering from the University of Leeds, UK in 1998. He received the M.Sc. degree from University Kebangsaan Malaysia in 2003 and Ph.D. degree from University of Leeds, UK for a thesis on the design and development of SIW filters in 2008. He is also an active researcher with a good track record with a number of research projects in RF and Microwave Engineering. He has published more than 200 journals and conference proceedings. Currently he is a Professor of Microwave Engineering in Universiti Teknikal Malaysia Melaka since 2018. 

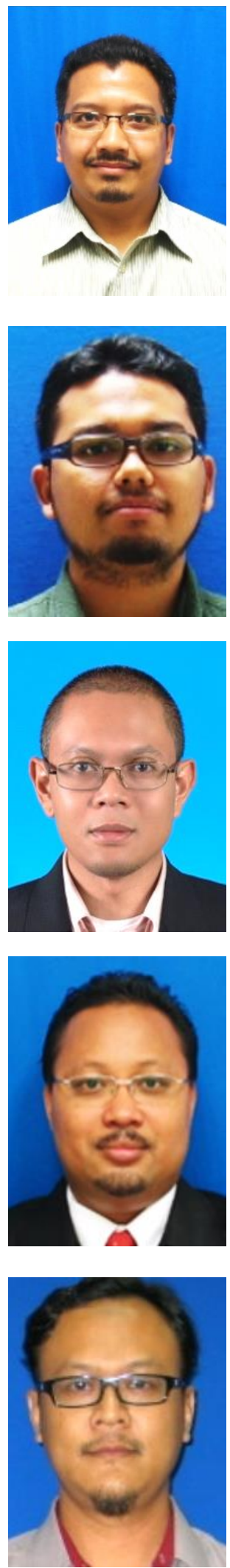

Noor Azwan Shairi was born in Malaysia. He received the Bachelor in Engineering (Electrical-Telecommunication) and the Master in Electrical Engineering from Universiti Teknologi Malaysia (UTM), in 2002 and 2005, respectively. In 2015, he obtained his Ph.D. degrees from Universiti Teknikal Malaysia Melaka (UTeM) in the field of Electronic Engineering (RF and Microwave). He is currently a Senior Lecturer at the Fakulti Kejuruteraan Elektronik dan Kejuruteraan Komputer (FKEKK), Universiti Teknikal Malaysia Melaka (UTeM), Malaysia. His research interests are RF switches, switchable/tunable filters, microwave sensors, antennas \& resonators.

Adib Othman was born in Malaysia in 1986. He is a $\mathrm{PhD}$ Candidate from Universiti Tun Hussein Onn Malaysia. He received the Bachelor of Engineering (Hons) Electrical from Universiti Teknologi MARA in year 2009. In 2015, he obtained his Master of Electrical Engineering in the field of Electromagnetic Compatibility from Universiti Tun Hussein Onn Malaysia. From 2015 to 2020, he was a lecturer at Fakulti Teknologi Kejuruteraan Elektrik dan Elektronik (FTKEE), Universiti Teknikal Malaysia Melaka (UTeM), Malaysia. His research interests are mainly focused on RF and Microwave Engineering.

Zahriladha Zakaria was born in Johor, Malaysia. He received the B. Eng. and M. Eng. in Electrical and Electronic Engineering from the Universiti Teknologi Malaysia in 1998 and 2004 respectively, and the $\mathrm{PhD}$ degree in Electrical \& Electronic Engineering from the Institute of Microwaves and Photonics (IMP), University of Leeds, United Kingdom in 2010. From 1998 to 2002, he was with STMicroelectronics, Malaysia where he worked as Product Engineer. He is currently a Professor at Faculty of Electronic \& Computer Engineering, University Teknikal Malaysia Melaka (UTeM).

Imran Bin Mohd Ibrahim is Senior Lecturer at Universiti Teknikal Malaysia Melaka and now serve as Head of Microwave Research Group. He received his bachelor, master and doctoral degree from Universiti Teknologi Malaysia, all in electrical engineering, in 2000, 2005, and 2016, respectively. He served as faculty's first Deputy Dean (Research and Post Graduate Study) and contributed to the early development of research activities at faculty and institution. He has lead several grants from industry, government and university in antenna research and wireless communication. He is also a committee member to draft the Technical Code in 5G Safety Radiation to Malaysia Technical Standard Forum Berhad.

Huda Bin A. Majid received the Ph.D. degree in electrical engineering from the Universiti Teknologi Malaysia (UTM). He worked as a Postdoctoral Fellow with UTM for a period of one year. He is currently a Senior Lecturer with the Faculty Engineering Technology, Universiti Tun Hussein Onn Malaysia (UTHM), Johor, Malaysia. He has published over 100 articles in journals and conference papers. His research interests include planar and flexible antennas, array antennas, reconfigurable antennas, metamaterial, and RF microwave and $\mathrm{mm}$ wave devices. 